See Article page 1303.

\section{Commentary: Aortic allograft for endocarditis: Prevention of recurrent infection or reconstructive solution?}

\author{
James A. Brown, MA, ${ }^{a}$ and Ibrahim Sultan, MD $^{\mathrm{a}, \mathrm{b}}$
}

Surgery for infective endocarditis (IE) of the aortic valve remains associated with high in-hospital mortality, which is estimated to be as high as $21 \%$, according to the Society of Thoracic Surgeons (STS) national database. ${ }^{1}$ Initial data for IE described outcomes of using aortic allografts, ${ }^{2-6}$ and many have enthusiastically endorsed their exclusive use in the setting of IE. Arguably, allogeneic biomaterial may be more resistant to recurrent infection than mechanical and xenograft implants. Lately however, this concept has been challenged by recent data suggesting that conventional prostheses-whether stented or stentless xenografts, or mechanical valves - may demonstrate similar long-term survival and freedom from recurrent IE, as compared with allograft implants. ${ }^{7-9}$ At the same time, STS data suggest that the use of aortic allografts and mechanical valves have been decreasing over time, whereas stented xenograft valve implantation is becoming more prevalent. ${ }^{1}$ As such, the controversy concerning the optimal prosthesis after debridement for IE persists.

In this issue of the Journal, Witten and colleagues ${ }^{10}$ significantly contribute to our understanding of the intrinsic risk of infection of cryopreserved allograft aortic root replacements. Critically, this study's population includes patients who received an allograft for nonendocarditis

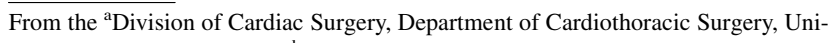
versity of Pittsburgh; and ${ }^{\mathrm{b}} \mathrm{Heart}$ and Vascular Institute, University of Pittsburgh Medical Center, Pittsburgh, Pa.

Disclosures: I.S. receives institutional research support from Medtronic and AtriCure. These conflicts are unrelated to this article. J.A.B. reported no conflicts of interest. The Journal policy requires editors and reviewers to disclose conflicts of interest and to decline handling or reviewing manuscripts for which they may have a conflict of interest. The editors and reviewers of this article have no conflicts of interest.

Received for publication May 8, 2021; revisions received May 8, 2021; accepted for publication May 10, 2021; available ahead of print May 14, 2021.

Address for reprints: Ibrahim Sultan, MD, Division of Cardiac Surgery, Department of Cardiothoracic Surgery, University of Pittsburgh, Center for Thoracic Aortic Disease, Heart and Vascular Institute, University of Pittsburgh Medical Center, 5200 Centre Ave, Suite 715, Pittsburgh, PA 15232 (E-mail: sultani@upmc.edu). J Thorac Cardiovasc Surg 2023;165:1318-20

$0022-5223 / \$ 36.00$

Copyright (C) 2021 by The American Association for Thoracic Surgery https://doi.org/10.1016/j.jtcvs.2021.05.016

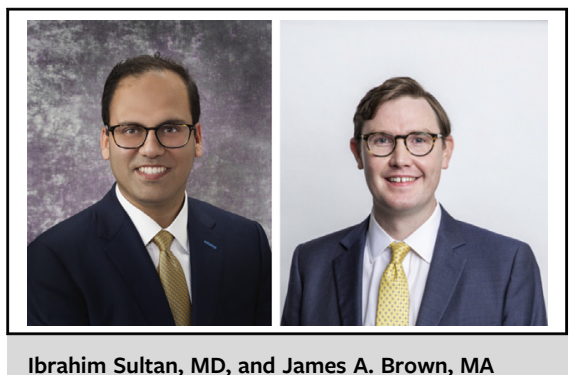

CENTRAL MESSAGE

While the present study charac-

terizes the intrinsic risk of infec-

tion for aortic allografts, its

comparative resistance vis-à-vis

conventional implants remains

undetermined.

reasons, as well as for IE. That is to say, this study exclusively analyzes aortic allografts and does not compare aortic allografts with conventional prostheses, such as xenograft or mechanical valves. The nonendocarditis group therefore does not constitute a "control" group but rather serves to contribute to our understanding of the intrinsic risk of cryopreserved aortic allografts for becoming infected. Nevertheless, the authors analyzed 2110 allografts, finding that the probability of allograft infection was $5.6 \%$ in patients without endocarditis, whereas it was $14 \%$ in patients with endocarditis, at 20 years of followup. The authors reasonably conclude that this constitutes a cumulatively low rate of infection and therefore justifies the continued use of allografts for patients with IE as well as without endocarditis.

The greatest virtue of this study is the large sample size, although this observation is tempered by the fact this series represents a rather heterogenous population spanning an extremely long time frame (1987-2017), with changes in cryopreservation methods, surgeon comfort with radical debridement of infected tissues, and operative technique for allograft implantation occurring over this timeframe. Their sophisticated statistical analysis has contributed to a nuanced understanding of the intrinsic risk of infection for aortic allografts. First, the authors accounted for the competing events of patient death, as well as allograft explantation for nonendocarditis reasons (eg, valve degeneration). In addition, the authors used the hazard function (in contradistinction to the event rate) to determine whether the risk for becoming infected changes over the early and 
late postoperative time periods. The authors should be congratulated for the excellent outcomes, the size of this series, and the nuanced statistical analysis.

Using the hazard function, the authors demonstrate that allografts implanted for IE harbor an early risk of developing recurrent endocarditis, which peaks around 6 months after the index operation but decreases around 2 years. This early peak contradicts some previous data that report a constant hazard of infection ${ }^{2,11}$ but confirm other data describing a similar early peak hazard. ${ }^{3,12}$ Presumably, the early risk of recurrent infection is prominent before endothelialization of the allograft implant. However, this phenomenon was not evident in the group of patients that received an allograft for nonendocarditis reasons; thus, the discordant hazard functions in the early postoperative time period deserves further investigation. Perhaps inadequate debridement of infected tissue or incomplete sterilization may also account for the early peak in patients with IE compared with patients without endocarditis. Interestingly, however, only $18 \%$ of the IE group was reinfected with the same organism that was cultured on initial presentation for their index operation.

Of note, there were no persons who injected drugs (PWID) in the nonendocarditis group, whereas $7.3 \%$ of the IE group were PWID. This is an important consideration, as mortality and reintervention in PWID is invariably greater than those that do not. For the group of patients receiving an allograft for IE, PWID was a risk factor for late recurrent allograft infection, when the risk of infection was low and constant. While the authors were unable to associate PWID with the early peak hazard for allograft infection, it would be interesting to know how the hazard function might change if PWID were excluded from analysis. Similarly, even though the authors explicitly compared cases before and after 2002 via traditional nonparametric Kaplan-Meier analysis, it would also be interesting to know if the contours of the hazard function might change if the authors excluded the earlier cases (eg, before 2002). This is especially pressing, since the only risk factor for the early peak hazard of infection was earlier surgery date. Nevertheless, the early peak hazard for allograft infection in the IE group and the observation that $82 \%$ of patients with IE were reinfected with a new organism are critical findings that deserve further investigation.

The authors are clear that this analysis only considers allografts. While it is not proper to call the nonendocarditis group a "control" group, it remains true that this study does not contain a control group and is therefore a singlearm study. As such, the optimal prosthesis for IE remains undetermined. A recent systematic review and metaanalysis suggests that conventional prostheses-whether stented or stentless xenografts, or mechanical valvesmay demonstrate similar long-term survival and freedom from recurrent IE as compared with allograft implants. ${ }^{7}$ Moreover, aortic allografts may be associated with greater risk of long-term reoperation for structural valve deterioration, although this phenomenon is far from evident. ${ }^{7}$ The current state of affairs therefore suggests that there may be sufficient clinical equipoise to conduct a prospective randomized controlled trial that explicitly compares aortic allografts with conventional prostheses. Critically, longterm survival, hemodynamic performance, thromboembolic event rate, risk of recurrent infection, and need for reoperation-for infectious as well as noninfectious reasons-need to be assessed, given the divergent considerations for prosthesis choice.

Finally, the authors have suggested in previous correspondence ${ }^{13}$ that removing allografts from the armamentarium for IE is premature, despite some data suggesting that allografts do not significantly reduce the risk of recurrent infection compared with conventional prostheses. The excellent results by Witten and colleagues certainly remind us that, in experienced hands, the allograft remains a relevant choice for surgeons and patients facing the difficult disease of IE. However, given the realization that aggressive debridement is likely the most important factor to ensure prevention of reinfection, it is likely the case that allografts will remain an essential prosthesis precisely because allografts afford more flexibility with respect to reconstruction of the outflow tract after aggressive debridement of infected tissue, as compared to conventional prostheses. ${ }^{14-16}$ In fact, STS data suggest that allografts remain a common choice for reoperative surgery (in the setting of prosthetic valve IE), as well as IE complicated by root abscess. ${ }^{1}$ However, while the present study by Witten and colleagues has helped characterize the intrinsic risk of recurrent infection for aortic allografts, the comparative resistance of allograft material to recurrent infection vis-à-vis conventional implants remains undetermined. Yet, the long-term low risk of infection and its utility after aggressive debridement of extensive infection argues for the continued use of allografts in the armamentarium for IE.

\section{References}

1. Savage EB, Saha-Chaudhuri P, Asher CR, Brennan JM, Gammie JS. Outcomes and prosthesis choice for active aortic valve infective endocarditis: analysis of the Society of Thoracic Surgeons adult cardiac surgery database. Ann Thorac Surg. 2014;98:806-14.

2. McGiffin DC, Galbraith AJ, McLachlan GJ, Stower RE, Wong ML, Stafford EG, et al. Aortic valve infection. Risk factors for death and recurren endocarditis after aortic valve replacement. J Thorac Cardiovasc Surg. 1992; 104:511-20.

3. Sabik JF, Lytle BW, Blackstone EH, Marullo AG, Pettersson GB, Cosgrove DM Aortic root replacement with cryopreserved allograft for prosthetic valve endocarditis. Ann Thorac Surg. 2002;74:650-9.

4. Niwaya K, Knott-Craig CJ, Santangelo K, Lane MM, Chandrasekaran K, Elkins RC, et al. Advantage of autograft and homograft valve replacement for complex aortic valve endocarditis. Ann Thorac Surg. 1999;67:1603-8.

5. Lopes S, Calvinho P, de Oliveira F, Antunes M. Allograft aortic root replacement in complex prosthetic endocarditis. Eur J Cardiothorac Surg. 2007;32:126-30 discussion 131-2. 
6. Musci M, Weng Y, Hübler M, Amiri A, Pasic M, Kosky S, et al. Homograft aortic root replacement in native or prosthetic active infective endocarditis: twenty-year single-center experience. J Thorac Cardiovasc Surg. 2010;139:665-73.

7. Yanagawa B, Mazine A, Tam DY, Jüni P, Bhatt DL, Spindel S, et al. Homograft versus conventional prosthesis for surgical management of aortic valve infective endocarditis: a systematic review and meta-analysis. Innovations (Phila). 2018; $13: 163-70$

8. Avierinos J-F, Thuny F, Chalvignac V, Giorgi R, Tafanelli L, Casalta JP, et al. Surgical treatment of active aortic endocarditis: homografts are not the cornerstone of outcome. Ann Thorac Surg. 2007;84:1935-42.

9. Kim JB, Ejiofor JI, Yammine M, Camuso JM, Walsh CW, Ando M, et al. Are homografts superior to conventional prosthetic valves in the setting of infective endocarditis involving the aortic valve? J Thorac Cardiovasc Surg. 2016;151:1239-46.

10. Witten JC, Houghtaling PL, Shrestha NK, Gordon SM, Jaber W, Blackstone EH, et al; on behalf of the Infectious Endocarditis Working Group. Aortic allograft infection risk. J Thorac Cardiovasc Surg. 2023;165:1303-15.e9.

11. Haydock D, Barratt-Boyes B, Macedo T, Kirklin JW, Blackstone E. Aortic valve replacement for active infectious endocarditis in 108 patients. A comparison of freehand allograft valves with mechanical prostheses and bioprostheses. $J$ Thorac Cardiovasc Surg. 1992;103:130-9.

12. Moon MR, Miller DC, Moore KA, Oyer PE, Mitchell RS, Robbins RC, et al. Treatment of endocarditis with valve replacement: the question of tissue versus mechanical prosthesis. Ann Thorac Surg. 2001;71:1164-71.

13. Hussain ST, Blackstone EH, Pettersson GB. Challenging allograft use for aortic valve infective endocarditis: is it the allograft or the surgeon? J Thorac Cardiovasc Surg. 2017;153:280-1.

14. Sultan I, Bianco V, Kilic A, Chu D, Navid F, Gleason TG. Aortic root replacement with cryopreserved homograft for infective endocarditis in the modern North American opioid epidemic. J Thorac Cardiovasc Surg. 2019;157: 45-50.

15. Mori M, Mahmood SUB, Schranz AJ, Sultan I, Axtell AL, Sarsour N, et al. Risk of reoperative valve surgery for endocarditis associated with drug use. J Thorac Cardiovasc Surg. 2020;159:1262-8.e2.

16. Habertheuer A, Geirsson A, Gleason T, Woo J, Whitson B, Arnaoutakis GJ, et al. STratification risk analysis in OPerative management (STOP score) for druginduced endocarditis. J Card Surg. April 24, 2021 [Epub ahead of print]. 